\title{
Protection chimique des plantes cultivées et durabilité *
}

\author{
Jean-Louis BERNARD \\ AFPP, Membre correspondant de l'Académie \\ $d^{\prime}$ Agriculture de France \\ 21, allée des Graviers de la Salmouille \\ 91190 Gif-sur-Yvette \\ <jlbernard.gif@orange.fr>
}

\begin{abstract}
The use of chemicals for crop protection starts in the middle of 18th century and increase after 1850 to avoid huge losses linked with the introduction of new vine and potato diseases or pests (e.g. vine downy and powdery mildew, Colorado beetle...). Before 1940, most of the fungicides, insecticides or herbicides are obtained from inorganic chemistry. The introduction of organic compounds increased after 1945. Nature of plant protection products range change after 1980 with an increasing percentage of new active ingredients (ais) based on natural active molecules (pyrethroids, tricetones...). At the end of the last century, the total number of ais registered in France reached 570. Following the implementation of EU review, we note a sharp decrease of ais number and diversity, quicker than the capacity of research to provide to their replacement. In 2010, choice could be limited in EU to less than 250 ais. This trend represents a major threat for agriculture if we want to maintain our capacity to manage minor and even major diseases, pests and weeds. To be sustainable, crop protection must use all the existing tools, mechanical, biological and chemical. In the future, sustainable use of chemicals appears to be linked with an approach based on integrated control principles including indirect protection measures - the maintain of a large panel of chemicals solutions to prevent resistances and to get the process of research creativity going.
\end{abstract}

Key words: sustainable crop protection, chemistry

\section{Protection des cultures : pourquoi la chimie?}

publique de cette thématique, associer protection chimique des cultures et durabilité peut sembler antinomique pour la plupart de nos concitoyens. Tant il est vrai que la chimie, cet art royal de transformer la matière dont ont rêvé les alchimistes et les puissants depuis l'Antiquité, a une image aujourd'hui devenue floue, ambiguë, et parfois même détestable à la lecture des quotidiens ou à l'écoute des informations radiophoniques ou télévisées. Comme si cette discipline qui a révolutionné la médecine et l'agriculture, qui a transformé en profondeur l'industrie du XXe siècle pour devenir omniprésente dans notre quotidien, était subitement devenue une menace absolue pour I'humanité.

Pour qui connaît cette discipline complexe qu'est la protection des cultures, il est parfaitement clair qu'elle ne se résume pas à de la chimie. Même si cette dernière est venue si souvent au secours des productions végétales que l'on tend parfois à faire des rapprochements simplificateurs. II est ordinaire d'entendre décrier cet amalgame, et ce d'autant plus fort que les critiques sont éloignées de l'agriculture. Ainsi notre société dénonce avec effronterie des pratiques dont elle ignore le plus souvent la raison d'être, tout en profitant allègrement des services qui en résultent au quotidien.

\footnotetext{
Texte de la communication présentée au sein de I'Académie d'agriculture, 13 février 2008 dans le cadre de la journée: "Comment la chimie peut favoriser une protection durable des cultures »
}

La protection des cultures plonge ses racines très loin dans le temps, sans doute aussi loin que I'agriculture elle-même. Les activités de désherbage se rencontrent ainsi chez tous les peuples, y compris les peuples sans écritures. Quelles qu'en soient les causes, on craint partout l'échec des semis. Partout, on cherche à effaroucher les oiseaux, à contrer les attaques de sauterelles, de "cantharides » et de chenilles, événements redoutés mais hélas ordinaires auxquels on pare de son mieux: par la prière et les sacrifices d'une part, par des actions correctives élémentaires comme la mise en place d'un épouvantail ou le ramassage des grosses larves d'insectes.

Le passé de nos agricultures est ainsi fait et peu de choses évolueront avant le XVIII ${ }^{\mathrm{e}}$ siècle. Bien sûr, les Grecs ont signalé les effets létaux de I'huile sur les insectes et les Romains ont décrit la toxicité de mélanges de bitume et de soufre ou de composés arsenicaux sur les chenilles de la vigne. Mais ces observations changent peu de choses dans le travail des paysans. Bien que connues des lettrés, ces recettes ne sont pas mises en pratique sur le terrain où la bonne levée des semis et la conduite du désherbage restent des préoccupations majeures.

Cependant, des idées et concepts originaux vont voir le jour dans la seconde moitié du XVII siècle. II y a tout d'abord en 1658 , les récriminations des paysans normands qui font adresser un mémoire au gouvernement via le parlement de Rouen demandant la destruction de l'épine-vinette (Berberis vulgaris). Cet arbrisseau très commun dans les campagnes est accusé de propager la rouille noire des céréales. Après débats, la demande sera finalement acceptée par Mazarin en 1660 et on verra dès lors flamber les épinettes partout en France. Peu de temps après, en 1670, le médecin Thuillier donne un mémoire à l'Académie de Paris où il est fait pour la première fois une relation entre mal des ardents, ergot du seigle et consommation de farine ergotée. Autre innovation, celle qui résulte du travail de Jean de La Quintinye qui prouve dans les jardins de Versailles les capacités aphicides des décoctions de tabac, s'inspirant d'études de médecine bien antérieures qui pointaient la toxicité extrême de ces extraits sur beaucoup d'animaux [1]. Ce remède sera progressivement développé dans les décennies suivantes au point que Le Berryais [2], en 1785, le recommande de manière ordinaire sur de nombreuses cultures.

Cela étant, la deuxième moitié du XVII et le début du XVIII ${ }^{\mathrm{e}}$ siècle sont marqués en Europe par des famines épouvantables, en raison principalement d'un climat froid qui gèle et pourrit les semis, de pluies continuelles qui jettent la nielle sur les céréales et couchent les moissons. Dans ce contexte de pénurie, les dégâts pourtant ordinaires des ravageurs des grains stockés n'en paraissent que plus insupportables. C'est alors que I'on commence à se pencher vers une nécessaire amélioration des cultures, incluant l'intérêt de trouver des solutions pour éviter la carie et le charbon des blés, améliorer la conservation des grains, mettre au point des 
semoirs en ligne pour faciliter le désherbage... Puis, comme le disait Voltaire : « vers l'an 1750 la nation rassasiée de vers, de romans, d'opéras... se mit enfin à raisonner sur les blés... ".

À cette époque, la majorité des gens très instruits attribue encore les maladies et affections visibles des végétaux à l'influence néfaste des astres, aux brûlures du soleil ou à la mauvaise qualité de l'air. Très originales sont les observations de Duhamel du Monceau qui désignent un champignon filamenteux comme responsable de la maladie du safran (1727) et proposent des mesures prophylactiques pour isoler les parcelles saines des champs malades. Plus tard, ses constats sur les maladies des céréales en feront l'un des fondateurs de la phytopathologie [3]. En 1755, Mathieu Tillet [4] précise le caractère contagieux de la carie et du charbon et teste sur les semences des lotions à base de chaux et de sel marin pour en réduire l'incidence. Ce premier pas anticipe la remarquable étude [5] de Bénédict Prévost qui démontre en 1807 la valeur du sulfate de cuivre, premier traitement de semences efficace contre la carie. Ces travaux sont d'autant plus intéressants que I'on disserte encore sur le fait de savoir si les champignons rencontrés dans les tissus d'un végétal naissent de l'hôte lui-même ou sont des organismes autonomes.

D'autres méthodes voient le jour. En Angleterre, vers 1800 , le jardinier Forsyth aurait utilisé [6] un mélange de soufre, de chaux, de tabac et de bourgeons de sureau avec de l'eau bouillante. La mixture obtenue, une fois refroidie, était réputée dotée d'un pouvoir curatif lorsqu'on l'appliquait avec des chiffons de laine sur des feuilles de pommier malades... Durant la première moitié du XIXe siècle, plusieurs sources font état de résultats positifs après aspersion ou lavage d'organes végétaux avec des associations de chaux et de soufre. Ils portent sur I'oïdium de la vigne (Kenrick, 1833), I'oïdium (en Irlande en 1824) [7] ou la cloque du pêcher (Knight, 1834) [8]. Ce «lime sulphur », très agressif pour le matériel et les végétaux, sera employé ultérieurement comme insecticide sur les cochenilles.

Avant 1850 , les moyens de lutte directe contre les ennemis des cultures soulèvent parfois des questions sur la toxicité pour l'utilisateur ou la sélectivité sur les végétaux, mais aucune question en matière de durabilité. La protection des plantes s'intéresse alors à des ennemis des cultures traditionnels bien connus des agriculteurs qui, tous, emploient de façon très hétérogène avec des fortunes diverses des méthodes prophylactiques (jachère, taille et brûlage....) et pratiquent la collecte manuelle des insectes (hanneton, chenilles, courtilière, anthonome...). Sur les céréales, et en dépit de l'importance des maladies transmises par la semence, on n'utilise encore que rarement le chaulage. Ce sont les horticulteurs qui sont à la fois les principaux artisans et les bénéficiaires d'une pharmacopée naissante. Ses balbutiements autour des sels de cuivre, du soufre et de la chaux prennent cependant place à une époque où la chimie industrielle amorce son développement. Elle repose encore largement sur la chimie minérale qui sera réactive dans les décennies suivantes pour offrir des facilités pour la fabrication des premiers fongicides.

\section{Les fléaux des cultures et l'extension de la protection chimique}

Une succession d'événements dramatiques survenus entre 1845 et 1920 des deux côtés de l'Atlantique a complètement modifié la manière de protéger les cultures. Pour l'Europe, nous connaissons bien l'histoire des fléaux successifs introduits du Nouveau Monde: mildiou de la pomme de terre, oïdium, phylloxera, mildiou et black-rot de la vigne, puis doryphore. Ces calamités ont été à l'origine d'un effort considérable pour y remédier avec la proposition d'un nombre invraisemblable de méthodes de lutte, la plupart sans résultat tangible. La génétique sera couronnée de succès avec la création de vignes hybrides résistant au mildiou ou/et au phylloxéra mais ces découvertes n'ont pas eu à ce jour de succès commercial en raison de la qualité discutable de leurs produits. Contre les maladies, la solution passera d'abord et pour plusieurs décennies par les fongicides minéraux à base de soufre et de sels de cuivre... et seuls des insecticides pourront contenir les pullulations du doryphore. Pour le phylloxéra, une protection rationnelle et durable ne sera pas obtenue par des moyens chimiques ou biologiques mais par la sélection de porte-greffes résistants et la pratique du greffage.

En Amérique du Nord, le commerce transocéanique a eu les mêmes effets. Les introductions anciennes de la cécidomyie destructive (Mayetiola destructor) et du carpocapse des pommes (Cydia pomonella) n'ont été que les prémices d'une immense vague d'arthropodes ravageurs venus de l'Ancien Monde. Comme le bombyx disparate (gypsy moth = Lymantria dispar), volontairement introduit de France en 1868 à des fins de travaux scientifiques et qui devient dès 1889 un fléau majeur des forêts; comme le Pou de San José (Aspidiotus perniciosus) apporté de Chine en Californie avec des arbres fruitiers vers 1870 ; comme le coléoptère japonais Popillia japonica, ravageur polyvalent découvert en 1912 dans le New Jersey où le transport par bateau de rhizomes d'iris l'avait introduit..., etc. Un des exemples les plus célèbres est celui de la pyrale (european corn borer $=$ Ostrinia nubilalis). Ce ravageur assez polyphage d'origine européenne est un lépidoptère qui a franchi l'océan vers 1910, vraisemblablement avec des lots de paille à balais importée d'Italie ou de Hongrie. Observé près de Boston en 1917, il a atteint les Grands Lacs en 1931 avant d'envahir toutes les régions d'Amérique du Nord où la culture du maïs était pratiquée. Aux États-Unis, il est encore responsable chaque année de plus de 700 millions d'euros de dégâts dont plus de 200 millions pour le seul état de Minnesota en 1995. Mais le danger vient aussi du vaste continent américain lui-même. Avec le charançon du coton (cotton boll weevil = Anthonomus grandis) qui, entré au Texas depuis le Mexique en 1892, atteint les domaines cotonniers d'Alabama en 1915 où il devient le principal ravageur de la culture, contribuant à accentuer la situation dramatique des agriculteurs du Sud à l'époque de la grande dépression des années 30 . Sans oublier le célèbre doryphore qui, parti de régions reculées des Montagnes Rocheuses, a suivi les plantations de pomme de terre le long du nouveau chemin de fer pour atteindre New York en 1874 d'où il gagne l'Europe et l'Asie. Cette liste est loin d'être limitative.

La réponse à cette marée montante des problèmes - que l'on exige forcément rapide - a été articulée de plusieurs manières :

- avec l'étude, la mise au point et le développement d'une pharmacopée: centrée sur la chimie avec des fongicides minéraux en Europe et des insecticides huileux ou minéraux aux États-Unis. En parallèle, d'autres agents insecticides ont aussi été étudiés comme la bactérie Bacillus thuringiensis découverte au Japon dès 1901 puis en Allemagne en 1911, des champignons antagonistes (ex: Beauveria sp.), des extraits végétaux comme le pyrèthre, la nicotine... En sus de leur activité propre, un usage conséquent des corps gras est fait au titre d'adjuvants, de mouillants... complément utile à diverses matières actives ;

- avec la recherche de macro-organismes, répresseurs naturels des ravageurs envahissants, les «pests", dans leur pays d'origine; après élevage et acclimatation, certains lâchers d'auxiliaires ont parfois été couronnés de succès. C'est le cas de coccinelles comme Rodolia (Novius) cardinalis, déterminante pour contenir la cochenille australienne ou d'hyménoptères comme Cales noaki contre l'aleurode floconneux des agrumes et Encarsia perniciosa contre le Pou de San José ;

- avec un travail de sélection pour préciser les variétés les plus résistantes à l'action des parasites: on connaît les fortunes diverses de I'hybridation en viticulture. Le travail pionnier de "sélection généalogique " que Louis de Vilmorin présente en 1856 devant I'Académie d'agriculture donne le coup d'envoi d'une activité au long cours visant à conférer aux plantes 
de grande culture une moindre sensibilité aux rouilles, au piétin-verse, etc.

- avec la création de dispositifs de quarantaine, illustrée par l'entomologiste américain L.O. Howard, en mission pour son gouvernement, qui précisait devant notre Académie d'agriculture [9] le 22 juin 1910 que « plus de 40 espèces d'insectes dangereux de première importance, causant chacun, annuellement, plusieurs millions de dollars de dommages aux récoltes, ont été introduits de pays étrangers, pour la plus grande part européens... ", dont récemment de France, le brown tail moth des arbres fruitiers $[10]^{2}$. L'encadrement réciproque des échanges de végétaux afin d'éviter l'explosion des contraintes liées à l'organisation des luttes est un dispositif indispensable mais hélas non suffisant pour éviter de nouvelles introductions dommageables.

En réponse à l'envahissement considérable des "mauvaises herbes» consécutif à l'emploi accru des matières fertilisantes, le désherbage chimique des cultures a commencé [10] avec les travaux de Louis Bonnet qui évalue les effets du sulfate de cuivre sur les dicotylédones adventices et sa sélectivité pour les céréales en 1896. Mais jusqu'en 1914, l'emploi de désherbants issus de la chimie se limitait à ces cultures et était bien loin de sa banalisation. À cette époque, la destruction des moutardes et autres dicotylédones dans les champs de céréales requiert des quantités importantes de sels minéraux: de l'ordre de $400 \mathrm{~kg} / \mathrm{ha}$ pour le sulfate de fer anhydre, $40 \mathrm{~kg} / \mathrm{ha}$ pour le sulfate de cuivre, $30 \mathrm{~kg} / \mathrm{ha}$ pour le nitrate de cuivre. Les méthodes "modernes » faisant appel à l'acide sulfurique demandent 80 à 120 litres d'acide à $65^{\circ}$ Baumé appliqués dans 1000 litres d'eau environ par ha. La compagnie St-Gobain, qui livre ce produit à la demande des acheteurs, en met à disposition chaque année plusieurs milliers de tonnes pour le seul Midi de la France. La Compagnie Bordelaise qui ravitaille le sud-ouest aurait vendu en wagonsciternes et bonbonnes de cent litres une quantité de l'ordre de 3500 tonnes pour la vallée de Garonne en 1926-1927 [11]. L'acide sulfurique sera I'herbicide le plus utilisé sur céréales en Europe avant 1940.

Ainsi donc, avant la Première Guerre mondiale, les éléments constitutifs de la protection des cultures moderne sont en place. Et cette évolution se trouve être la même dans tous les pays développés où la science agronomique avance vers des solutions en disposant déjà de toute la palette des méthodes que nous utilisons aujourd'hui. Si la chimie y trouve une place

\footnotetext{
${ }^{2}$ II s'agit du bombyx cul-brun (Euproctis chrysorhoea.) qui s'est répandu dans l'est des États-Unis après son introduction à Somerville, Massachusetts, en 1897.
}

importante malgré les coûts et les changements d'habitudes induits, elle le doit surtout à deux raisons. Tout d'abord, sa relative rapidité à porter remède à des fléaux importés au développement explosif. Que I'on songe au cas de I'oïdium de la vigne [12]. Ou encore au mildiou de la pomme de terre qui ravageait les cultures depuis plus d'un demi-siècle lorsque la mise au point de la bouillie bordelaise amena enfin avec les traitements cupriques un début de réponse suite aux essais conduits par Prillieux et Girard au champ d'expérience de l'Institut Agronomique de Joinville-le-Pont en 1888 [13]. Ensuite, au fait que bien souvent, elle constitue dans le moment une réponse économiquement rationnelle unique au problème posé. Le désherbage des céréales à l'acide sulfurique, si contraignant et dangereux soit-il en est une illustration. L'emploi des sels d'arsenic pour prévenir les dégâts de la carpocapse des pommes et de l'anthonome en est une autre.

Dès ses origines, la pharmacopée présente une image de dangerosité qu'elle ne quittera guère par la suite. Elle fait en effet très largement appel à des substances porteuses de connotations objectives ou subjectives inquiétantes. Ainsi, le soufre a des propriétés irritantes et traîne une réputation diabolique ; les polysulfures et l'acide sulfurique attaquent et corrodent le métal ; de nombreux sels de cuivre sont réputés toxiques (« vert-de-gris ») ; la nicotine, l'arsenic... sont connus comme de véritables poisons; les goudrons de houille sont excessivement malodorants. Mais si nous allons voir que la question des risques et de leur gestion est ancienne, celle de la durabilité ne commencera à se poser qu'alors que les esprits optimistes commençaient à croire que I'homme enfin, avait réussi à contrôler la Nature.

\section{La protection des cultures : de I'entre-deux-guerres à la chimie de synthèse}

Entre 1900 et 1945, l'agriculture a trouvé dans la chimie un début de réponse à des questions séculaires. À cette époque, l'armoire à pharmacie n'est pas bien garnie et nombre de recettes autour, par exemple, du pétrole et de ses dérivés, sont utilisées avec des objectifs très variés. $\mathrm{Si}$ on excepte les porte-bonheur et autres potions quasi magiques, l'agriculteur dispose pour protéger ses cultures d'un ensemble de moyens rationnels plus ou moins mis en œuvre que l'analyse des ouvrages de vulgarisation de cette période permet de résumer comme suit : - Choix de variétés résistantes aux maladies ou aux ravageurs dominants lorsqu'elles existent. - Ramassage suivi de destruction ou de brûlage : élimination directe $d$ 'insectes nuisibles comme les vers blancs (hannetonnage), les nids de chenilles, les anthonomes, piérides, balanins, courtilières... ; conseillé lors de la taille pour les rameaux d'arbres fruitiers infestés de cochenilles, de monilioses...

- Piégeage des ravageurs à l'aide de pots, de fagots contenant un attractif alimentaire, de bandes engluées... Le piégeage lumineux, forcément non sélectif, est recommandé dans les vignes ou les potagers. Des cultures leurres sont parfois proposées pour éloigner les ravageurs de certaines productions.

- Méthodes diverses faisant appel à des moyens physiques ou à des travaux mécaniques: comme par exemple le labour à la bêche, le déchaumage, le labour ou le travail du sol superficiel pour combattre adventices et ravageurs du sol; le battage des grains au tarare à grande vitesse pour tuer l'alucite; le bassinage des cultures sous abri pour limiter la prolifération des acariens... etc.

- Des moyens radicaux comme le changement des semences, la modification des rotations, la jachère ou l'abandon temporaire de culture.

En regard de ces méthodes traditionnelles, une place croissante est faite à des traitements chimiques appliqués par pulvérisation, poudrage ou arrosage qui font massivement appel à des solutions issues de la chimie minérale (tableau 1). Marginalement, cette pharmacopée « recommandable » fait place à des recettes étranges proposées par la recherche officielle ou les fournisseurs privés. Comme les poudrages à répétition sur des supports de talc, de soufre ou de chaux, l'arrosage des plants avec des solutions de nicotine ou de sulfocarbonate de calcium, l'aspersion du sol avec des huiles de vidange ou cette recommandation de traiter le pou rouge de l'oranger avec des pulvérisations savonneuses nicotinées, des émulsions de pétrole, des polysulfures ou le mélange « huile d'auto usagée 1 litre + farine $1 \mathrm{~kg}$ + eau 100 litres».

Cela étant, les auteurs citent assez souvent les oiseaux, les taupes, etc. comme des auxiliaires que l'agriculteur doit protéger. Mais si la possibilité de tirer parti d'arthropodes « utiles » est donnée comme un succès de la recherche au travers d'exemples emblématiques (ex : I'hyménoptère Aphelinus mali introduit en 1920 pour lutter contre le puceron lanigère), aucune référence $n^{\prime}$ est faite à une action concertée en direction des praticiens afin de les favoriser.

On doit noter que pour beaucoup de grandes cultures (ex : blé, orge, maïs, lin) le cortège des parasites et surtout des ravageurs est dès cette époque bien connu et inventorié. Mais, sur ces cultures, aucune lutte chimique n'est généralement préconisée, hormis le désherbage des céréales. L'organisation de luttes faisant appel à des substances chimiques concerne prioritairement les cultures forcées, les légumes en maraîchage, la vigne et les vergers. 
Tableau 1. Produits majeurs de la pharmacopée chimique des années 1930-1939 (Sources : revues de vulgarisation diverses dont le Guide Pratique pour la Défense sanitaire des végétaux).

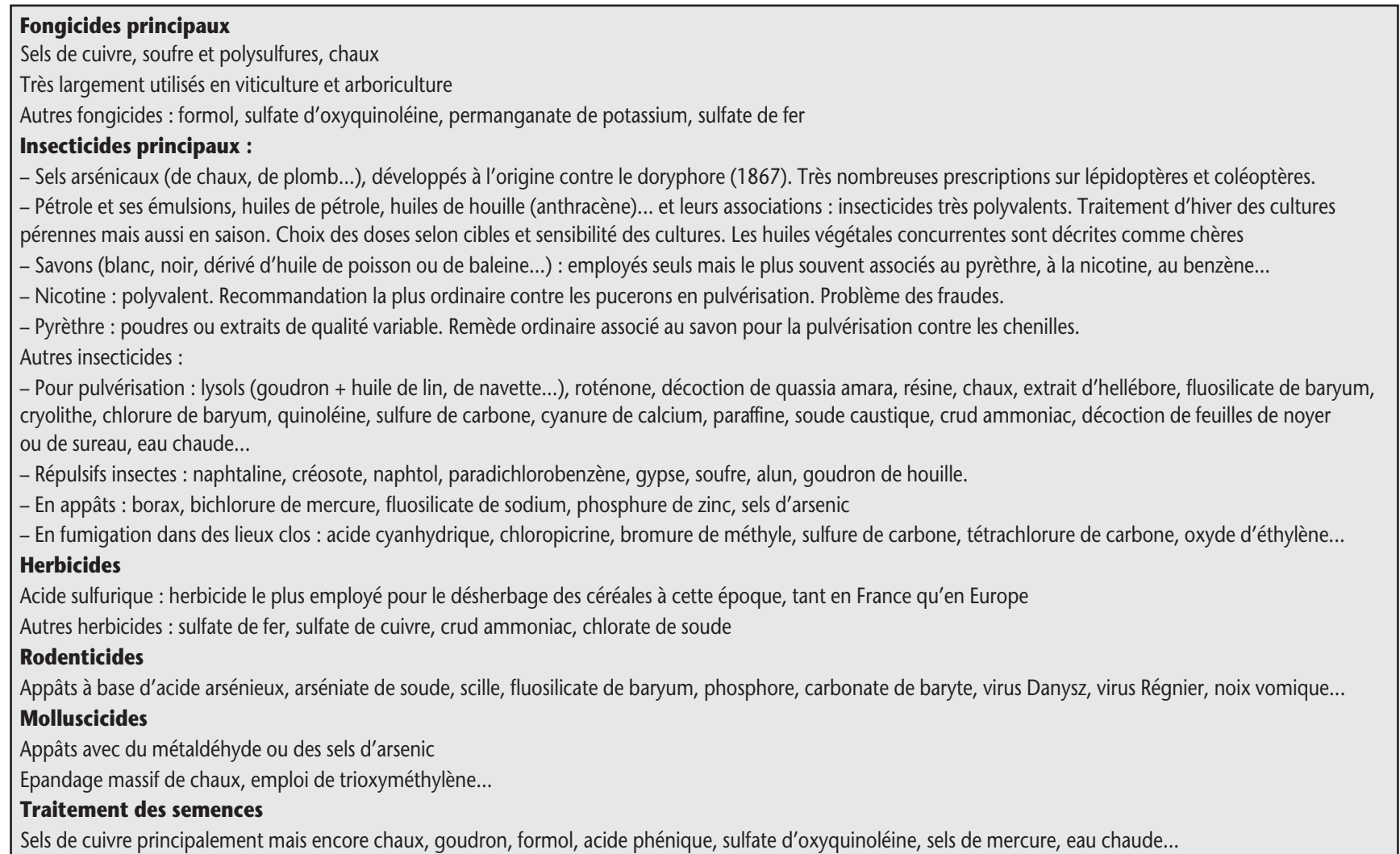

Dans ce contexte, l'arrivée de produits issus de la chimie de synthèse dès 1946 (phytohormones) a été vécue comme une révolution. Pour les cultivateurs et les services officiels, elle laissait espérer des solutions économiques à tous les problèmes. L'expérience a depuis prouvé $q u^{\prime}$ en protection des cultures, les solutions simples n'existent guère et que chaque percée de l'innovation génère ses propres inconvénients. Pour contenir les bio-agresseurs, la nécessité de disposer et de véritablement utiliser une palette de moyens divers reste un principe qui, même en 2008, n'est pas encore totalement entré dans la pratique.

\section{Durabilité : de l'émergence d'un concept à la définition d'une protection durable des cultures}

En 1987, le rapport Brundtland a proposé le concept de développement durable comme étant celui « qui répond aux besoins du présent sans compromettre la capacité des générations futures à répondre aux leurs ». II repose sur trois composantes indissociables dont la prise en compte au niveau politique doit être équilibrée. Ces trois dimensions sont l'économique, le sociétal et l'environnemental. L'agriculture durable (ou soutenable) est l'application à l'agriculture des principes du développement durable. Elle se définit comme un système de production qui vise à assurer de façon pérenne une production de nourriture, de bois et de fibres en respectant les limites économiques, sociales et écologiques qui en assurent la maintenance dans le temps.

Que peut être en regard de ces piliers une protection des cultures durable?

Signalons tout d'abord que le principe même de protéger les cultures est indissociable des dimensions économiques et sociétales d'une agriculture durable. Les aléas de grande ampleur parfaitement prévisibles qui découleraient d'une absence de mesure visant à contenir les principaux bio-agresseurs se traduiraient très vite pour l'agriculteur par un cul-de-sac économique et la fin de son activité d'exploitant. Pour le citoyen, des coûts alimentaires plus élevé, des crises de qualité alimentaire voire la sécurité même de l'approvisionnement deviendraient très vite problématiques.
Rappelons ensuite que protéger les cultures est une discipline complexe qui fait appel à toute la palette du savoir agronomique pour minimiser I'impact des bio-agresseurs : adventices, maladies cryptogamiques, bactériennes ou virales, ravageurs divers... II est évident qu'entre eux, une hiérarchie locale doit être clairement établie de manière à orienter le système de culture afin de contrer l'action des nuisibles les plus fréquents et les plus préjudiciables.

C'est pour minimiser leurs dommages que l'agriculteur doit mettre en œuvre de façon volontariste et cohérente un ensemble de mesures indirectes et de moyens directs de protection [14]. Les mesures indirectes de protection ont pour objectif de minimiser ou de rendre impossible l'expression de la nuisibilité potentielle des bio-agresseurs considérés. Elles comprennent :

- Des mesures appliquées à l'espèce cultivée ou à sa conduite pour favoriser son auto-défense : choix de variétés résistantes, de semences ou de plants sains, dates de semis, rotations...

- Des mesures appliquées à l'environnement de la plante cultivée destinées à renforcer le végétal ou à rendre son infection plus difficile: drainage, fumure, travail du sol... 
- Des mesures appliquées à l'organisme à combattre en dehors de sa période de nuisibilité afin d'en diminuer le potentiel néfaste : élimination des abris, des plantes relais ou des foyers primaires, réduction du niveau d'inoculum...

Les moyens directs de protection sont ceux qui visent à éloigner ou à combattre les bioagresseurs indésirables en situation de nuire. Ils comprennent :

- Des procédés physiques de défense : effarouchement, capture, chasse, destruction par le travail manuel ou mécanique, le feu...

- Des procédés biologiques de défense : lâchers d'auxiliaires, utilisation de champignons antagonistes...

- Des procédés chimiques de défense visant précisément l'organisme combattu en période de nuisibilité: répulsifs, fongicides, confusion sexuelle..

Dans une telle approche, la chimie n'est qu'un moyen parmi d'autres pour l'obtention de l'objectif et ne saurait être la réponse automatique à toute difficulté survenant dans le développement d'une culture. Cela étant et quel que soit le système de production, il existe des domaines où ce recours est presque incontournable comme le contrôle du mildiou, de l'oïdium où des cicadelles en viticulture, celui de la tavelure du pommier, de la cloque du pêcher...

Il convient aussi d'éviter la confusion fréquente entre caractère préventif ou curatif d'une action. Elle ne saurait se définir au travers de la vision simpliste: "préventif $=$ non chimique = alternatif $»$ et " curatif $=$ chimique ou non chimique ». En reprenant un exemple sur le pommier, si le curetage manuel des chancres à Nectria est souvent mentionné comme une action de type préventif, l'application concomitante d'une peinture fongicide tout aussi préventive par rapport à un nouveau cycle infectieux du champignon est souvent assimilée, parce que faisant appel à un produit chimique, à une méthode de lutte directe. De même, il faut noter que le même outil de travail du sol peut être utilisé soit comme un moyen direct, soit dans le cadre d'une mesure indirecte. Ainsi, l'enfouissement des graines de vulpin par un travail mécanique avant un semis de blé d'hiver est une mesure indirecte de protection alors que le binage mécanique destiné à éliminer le vulpin après sa levée dans la culture est un moyen palliatif direct.

Une protection durable des cultures pourrait donc être définie comme la mise en œuvre par l'agriculteur d'un ensemble cohérent de mesures indirectes et de moyens directs destinés à minimiser l'incidence des bio-agresseurs sur le rendement et la qualité des productions et permettant à la fois d'assurer la pérennité de l'exploitation agricole, de satisfaire les attentes économiques et sociétales, tout en exerçant sur l'environnement des effets transitoires qui n'hypothèquent pas à moyen et long terme la diversité du vivant inféodé à l'écosystème agricole préexistant.

\section{Protection chimique et durabilité}

Hormis de rares situations d'agriculture de subsistance, aucun système productif de par le monde n'a pu cultiver à ce jour de façon économique et durable sans dispositif de protection contre les bio-agresseurs. Dans tous les pays agricoles développés, la chimie occupe une place dans les solutions retenues, place dont l'importance varie selon le système de production, la nature des bioagresseurs, l'importance de leur pression et l'efficience des moyens alternatifs disponibles.

En matière de durabilité, chacun des domaines suivants est donc questionnable en toutes situations :

- efficacité et intérêt économique : quelle est la valeur des solutions utilisées à court et moyen terme en regard d'autres méthodes?

- sécurité pour I'homme, qu'il soit utilisateur des produits agropharmaceutiques ou consommateur des denrées traitées

- environnement : biodiversité, eau, sols, air..., - acceptation sociétale des méthodes utilisées. Avant d'aborder ces différents aspects, nous devons retracer en quelques lignes les évolutions récentes de la pharmacopée qui en est issue.

\section{Les grandes évolutions de la pharmacopée chimique}

Après la seconde guerre mondiale, si un nombre croissant de produits chimiques de synthèse a été proposé par la recherche aux agriculteurs, nous savons que ces solutions sont quelquefois devenues une réponse unique pour certains de leurs problèmes faute $d^{\prime} u n e$ approche cohérente du système de protection. D'où la mise en cause au début des années 1960 de certaines substances actives comme les fongicides dérivés du mercure, les insecticides organochlorés et organophosphorés, dans un temps où la pharmacopée était en pleine période d'innovation.

Sur la période que nous considérons, entre 1965 et aujourd'hui, plus de 800 « solutions » ont été inscrites ${ }^{3}$ sur la liste des moyens autorisés. Toutes ces solutions ne sont pas des substances phytopharmaceutiques classiques (her-

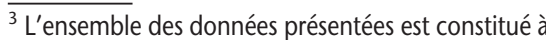
partir de l'Index phytosanitaire de I'ACTA (années 1965, 1970, 1980, 1990, 2000 et 2008. Les digressions sur 2010 prennent en compte des données officielles publiées à ce jour.
}

bicides, fongicides, insecticides et acaricides). On y trouve des substances destinées à I'hygiène des élevages, à la désinfection des locaux, à l'élimination de la mousse dans les pelouses, des rodenticides, des répulsifs, des produits pour la démoustication, des régulateurs de croissance, des hormones de bouturage, des phéromones pour la confusion sexuelle ou l'agrégation, des phytoprotecteurs, ainsi qu'une quantité d'adjuvants extemporanés pour bouillies, des mouillants, etc. Par ailleurs, les arthropodes auxiliaires proposés à la vente ont été progressivement soumis à des règles $\mathrm{d}^{\prime} \mathrm{AMM}$ et $\mathrm{s}^{\prime}$ ajoutent à la liste. Cette diversité des moyens nous conduira parfois à parler de «solutions" (produits chimiques et autres) ou à regrouper sous un même objectif (ex: protection contre les ravageurs) des moyens chimiques ou biologiques.

Pendant près de cinquante années, le nombre des solutions chimiques ou biologiques proposées aux agriculteurs a été constamment à la hausse en raison de la créativité des laboratoires de recherche. Ce n'est plus aujourd'hui le cas en dépit du fait que de nombreux auxiliaires (plus de 60 en 2008) ont été introduits dans la liste des solutions couvertes par une AMM (tableau 2).

L'essentiel de cette régression concerne les molécules composant la pharmacopée chimique. Les causes apparentes sont multiples:

- coût élevé de la recherche ;

- difficulté d'obtention des homologations avec des délais parfois très supérieurs à 10 années après le dépôt du brevet, sachant qu'une prise de brevet « protège » I'obtenteur pour 20 ans;

- revue européenne des substances actives qui élimine de nombreuses molécules anciennes pas toujours remplacées par des solutions efficaces pour les usages correspondants ;

- concurrence des pays à bas coût qui mettent en marché des génériques, parfois avant même la chute du brevet.

La diminution du nombre des solutions chimiques disponibles concerne les trois grandes catégories [15] (figure 1).

II n'en demeure pas moins que la pharmacopée française reste une des plus modernes du monde.

Si on considère par exemple la catégorie des insecticides et acaricides, on constate que plus de la moitié des solutions chimiques a été inscrite après 1990 (figure 2). Pour cette catégorie, on peut prévoir que sur les 70 molécules autorisées en 1965, il n'en subsistera plus que 4 ou 5 sur le marché en 2010. De même, sur les 103 molécules autorisées en 1980, il n'en subsistera plus qu'une quinzaine à la même époque. Le renouvellement qui a concerné les produits de synthèse touche aussi les produits dits « naturels » puisque la nicotine et la roténone utilisés 
Tableau 2. Nombre de solutions proposées pour la protection des plantes cultivées et des denrées stockées (source: Index phytosanitaires des années correspondantes).

\begin{tabular}{|lcccccc|}
\hline 1965 & $\mathbf{1 9 7 0}$ & $\mathbf{1 9 8 0}$ & $\mathbf{1 9 9 0}$ & $\mathbf{2 0 0 0}$ & $\mathbf{2 0 0 8}$ & $\mathbf{2 0 1 0}$ \\
\hline 183 (chimie à plus de 95 \%) & 250 & 330 & 463 & 570 & 506 & $\begin{array}{l}\text { Vers } \pm 400 \\
\text { solutions ? }\end{array}$ \\
\hline
\end{tabular}

avant 1940 (tableau 1) ont fait, elles aussi, I'objet de mesures de retrait. Ce rajeunissement est sensiblement le même dans l'univers des herbicides et dans celui des fongicides, malgré la place importante qu'occupent toujours les sels de cuivre et le soufre.

La nature même des substances actives issues de la chimie a elle aussi beaucoup évolué. En
1965, la pharmacopée essentiellement d'origine minérale des années 30 avait évolué vers des molécules pour la plupart issues de la chimie de synthèse et sélectionnées selon les méthodes du tri ("screening») de hasard. L'exemple des insecticides et acaricides utilisables pour la protection des cultures en plein air est illustré par la figure 3 .

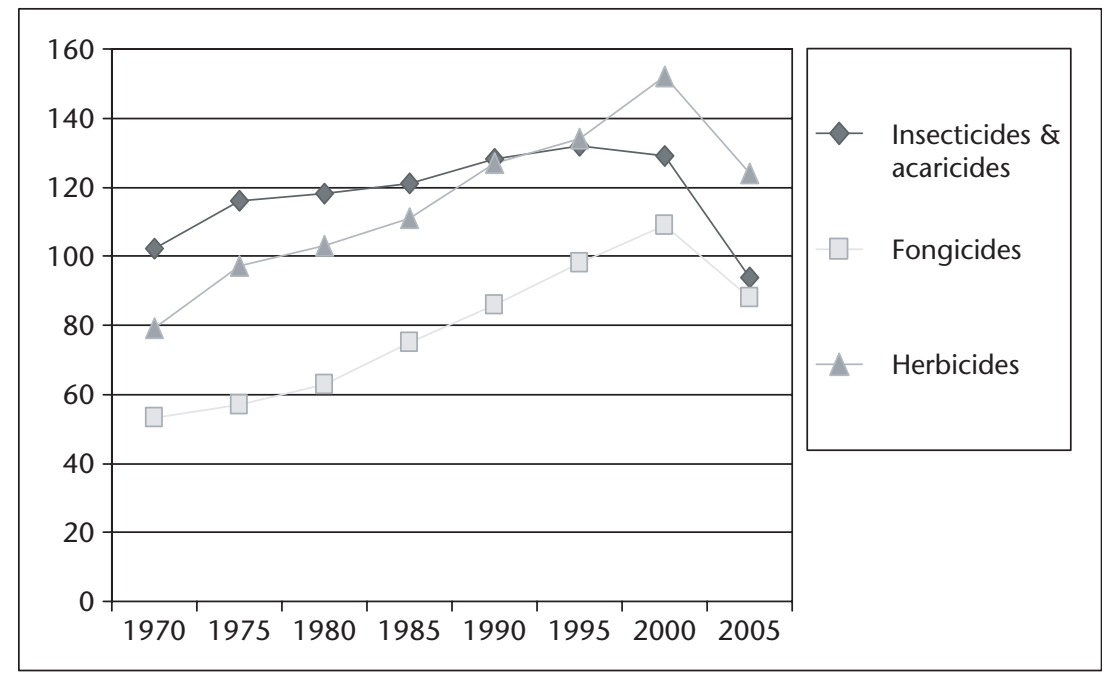

Figure 1. Nombre de molécules chimiques commercialisées sur le marché français par grande catégorie. Source: E. Barrié.

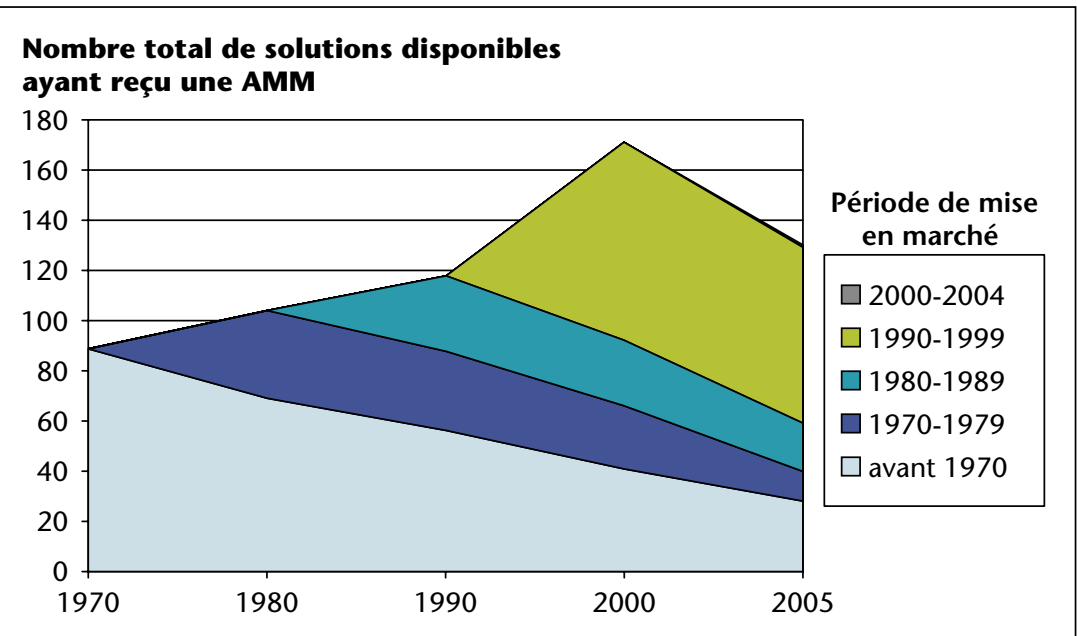

Figure 2. Nombre de solutions disponibles pour la protection des cultures contre les ravageurs (insectes et acariens) selon leur ancienneté de conception - En France pour la période 1970-2005.

Source: E. Barrié.

Contexte économique et efficacité des solutions chimiques dans une optique de durabilité

Une des raisons du succès des produits chimiques en protection des cultures provient du fait que ces solutions ont permis d'apporter des réponses économiques à certaines contraintes ancestrales (ex : lutte contre les adventices ou les hannetons) et de limiter, voire de supprimer, des tâches pénibles pour lesquelles il devenait impossible de trouver du personnel (ex : sarclage manuel, hannetonnage). S'interroger sur la durabilité technico-économique des solutions chimiques ne peut se faire en invitant simplement à un retour complet en arrière. En effet, le désherbage mécanique est jugé le plus souvent comme insatisfaisant [16] et l'agriculteur européen devient dorénavant rebelle aux travaux ingrats et répétitifs qui faisaient le quotidien de nos ancêtres.

Cependant, les produits de protection des cultures, vécus dès l'origine par le cultivateur comme une dépense "supplémentaire ", sont donnés comme toujours chers pour celui qui doit les acquérir. Ils représentent une part très variable des charges opérationnelles ${ }^{4}$ selon I'orientation technico-économique des exploitations: de 5,8\% en maraîchage à 25,2\% pour les systèmes céréales et oléoprotéagineux. Cela étant, leur prix tend à diminuer régulièrement. La communication des services économiques de l'APCA sur la base de données INSEE montre que leur valeur, basée sur un indice 100 en 1980 (monnaie constante) est rendue à 72 en 2005 [17]. Et ce, en dépit des retraits survenus pour des spécialités anciennes d'un coût restreint qui contraignent les professionnels à se reporter vers des produits plus récents, non encore amortis et souvent plus onéreux. En fait, leur choix est fait à partir de critères d'efficacité et de praticité dans le contexte économique du moment mais aussi, et il ne faut jamais l'oublier, en fonction de la réponse qu'ils offrent pour simplifier le travail, réduire la durée des tâches et leur pénibilité physique. Les solutions alternatives seront toujours évaluées par l'agriculteur en fonction de cette double appréciation.

Parmi les éléments qui militent en faveur de la réponse souple que procure la chimie se trouve la nécessité de contenir les nouveaux ennemis potentiels des cultures qui apparaissent régulièrement avec l'extension des échanges intercontinentaux ${ }^{5}$. Pour les seuls ravageurs, entre janvier 2000 et juin 2005, 41 espèces nouvelles ont été introduites sur le territoire national [18]

\footnotetext{
${ }^{4}$ Fournitures (engrais, phytosanitaires, semences...) + charges de personnel + travaux par des tiers + entretien et réparation du matériel.

${ }^{5}$ Voir www.europe-aliens.org
} 


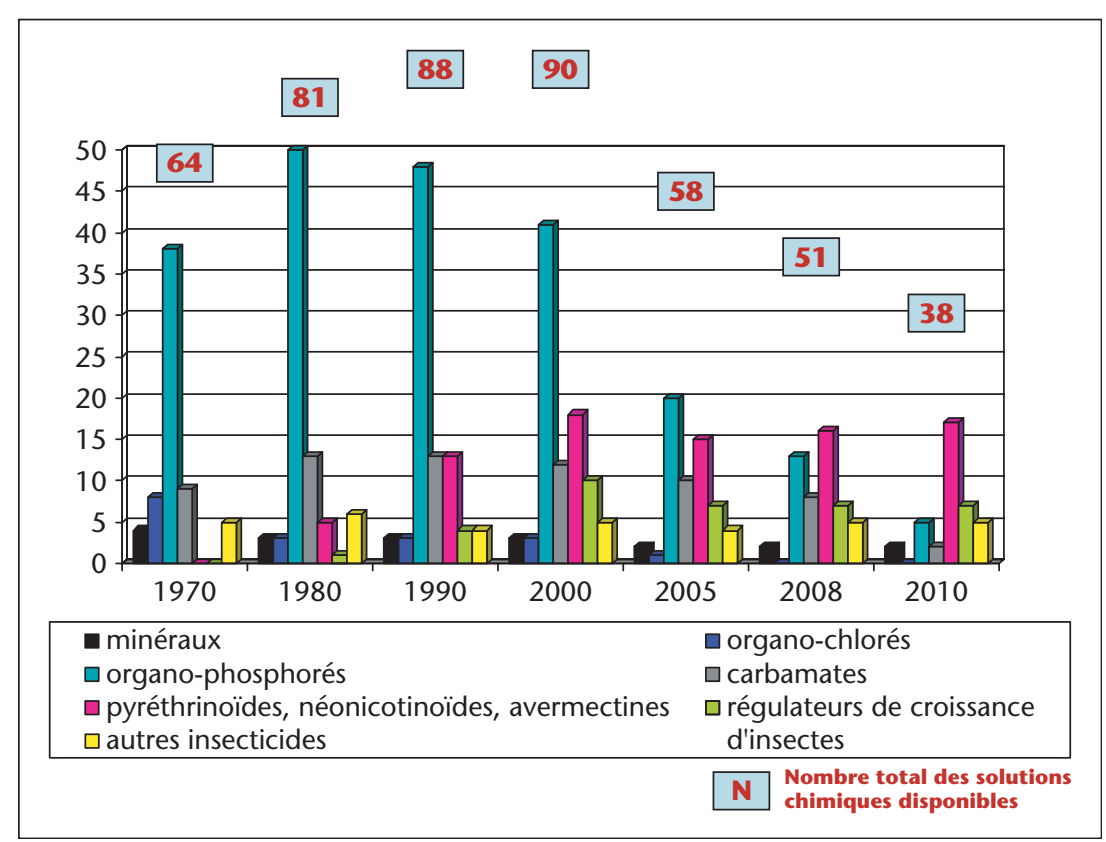

Figure 3. Nature et effectif des substances actives insecticides et acaricides utilisables pour la protection des cultures de plein air en France.

dont Diabrotica virgifera, la redoutable chrysomèle du maïs. Cette mondialisation du parasitisme transforme sans arrêt la donne pour l'agriculteur ou le pépiniériste. Disposer d'une gamme de produits diversifiés et encadrés est nécessaire pour parer à certaines situations, éviter les fraudes, voire les crises.

En matière de durabilité, le critère efficacité est très souvent questionné à deux niveaux : celui du manque de moyens qui peut guetter à terme si l'appauvrissement des solutions de défense se poursuit et celui de la perte d'efficacité résultant de l'apparition et de l'extension de phénomènes de résistance. Les deux sont en fait liés.

Jusqu'au début des années 2000, l'augmentation du nombre et de la diversité des produits chimiques a permis d'étendre la palette des solutions disponibles. Depuis plus de 25 ans, une bonne part de cette expansion s'est faite avec des molécules organiques créées par les laboratoires en raison de leur activité spécifique sur des sites enzymatiques précis, précision qui permet de maitriser au mieux les risques toxicologiques et écotoxicologiques. L'emploi privilégié de telles solutions au détriment de produits plus anciens à action multisites ou la disparition de ces derniers réduit les possibilités de choix de l'agriculteur et le conduit à privilégier des moyens dotés de propriétés certes intéressantes mais susceptibles de voir leur activité s'effondrer par suite d'un recours trop fréquent aux mêmes familles chimiques. Ce phénomène de mieux en mieux connu existe aussi bien pour les produits chimiques que pour les produits biologiques. Le célèbre Bacillus thurin- giensis a montré depuis 1985 des défaillances là Ensuite, on connaît des situations où l'adaptation de la flore microbienne des sols se traduit par une dégradation trop rapide de certains insecticides. C'est le cas de vastes zones du sud-ouest où il a fallu maintenir l'emploi des insecticides du sol organophosphorés en raison de la perte d'efficacité des carbamates.

En Europe, les risques d'une expansion préjudiciable des résistances concernent beaucoup de cultures: les productions sous abri ou des cultures pérennes (vigne, pommier) mais aussi des cultures annuelles. II en est ainsi par exemple des céréales et du colza avec la résistance des adventices aux familles d'herbicides antigraminées modernes (groupe des "Fop's", sulfonylurées).

Faute de pouvoir maîtriser la diversification et l'expansion du parasitisme, la durabilité de l'efficacité des solutions chimiques repose donc :

- sur le maintien en marché d'une palette de solutions suffisamment large, comprenant des produits spécifiques mais aussi des multisites ; - sur leur emploi de mieux en mieux ciblé qui évite les applications inutiles;

- sur l'organisation d'une alternance des substances actives dans le temps et dans l'espace ; des praticiens pour que la protection chimique ne soit utilisée qu'en succession de mesures indirectes réalistes que tout professionnel devrait connaître et mettre en œuvre. où il était utilisé de manière trop exclusive. - sur une formation sérieuse des conseillers et

\section{Préservation de l'environnement et durabilité de la protection chimique}

Toute activité agricole a un impact sur l'environnement. Le simple fait de travailler le sol ou $d^{\prime}$ uniformiser le milieu en semant des espèces précises sur une grande étendue exerce de fait une pression sur les biocénoses et leur état antérieur d'équilibre relatif. Certaines espèces vivantes s'en trouvent favorisées, d'autres fragilisées. La circulation des eaux, la dynamique d'évolution du sol, le cycle du carbone sont toujours affectés. Dans une optique de durabilité, il convient de s'assurer que ces effets inévitables ne sont pas préjudiciables à long terme aux écosystèmes agricoles.

Dans notre domaine, le point de départ est assurément le débat des années 60 autour des insecticides organochlorés. La prise de conscience de leur potentiel d'accumulation dans les chaînes alimentaires a abouti d'une part à un arrêt justifié de leur utilisation irraisonnée, d'autre part, à jeter un doute sur l'ensemble des «pesticides chimiques» qui perdure de nos jours dans la quasi-totalité des médias.

Parmi les domaines clés du débat, on retiendra principalement :

- la préservation de la diversité du vivant (biodiversité), en prenant comme illustrations le gibier et les arthropodes auxiliaires ;

- le maintien de la fonctionnalité des sols ;

- la protection de la qualité de l'eau.

\section{Biodiversité}

La conservation de la biodiversité est un sujet sur lequel il est délicat de communiquer en raison d'une charge affective qui pèse très lourd en regard de la méconnaissance généralisée de la phytopharmacie. Par ailleurs, mesurer l'impact des produits chimiques (comme de toute pratique agricole) sur les espèces vivantes terrestres est un exercice extrêmement difficile en raison du nombre des espèces que I'on considère et de leur écologie (capacité variable de fuite et de recolonisation), des ressources alimentaires ou des possibilités de refuge que leur procure le paysage agricole. Cette évaluation serait a priori plus simple pour les milieux aquatiques fermés (mares, étangs).

Prenons comme premier exemple le gibier. La France dispose depuis 1986 du réseau SAGIR qui permet de diagnostiquer les causes de mortalité au sein de la faune sauvage et de mieux connaître leur rôle de réservoir potentiel ou de vecteur pour les maladies transmissibles à I'homme ou aux espèces domestiques. Dans cet examen, les causes majeures de mortalité comme la prédation et les maladies banales (ex : myxomatose du lapin) ne sont pas prises en compte et les causes traumatiques sont notoirement sous-évaluées. Les intoxications reliées aux produits de protection des plantes apparaissent mineures, très certainement infé- 
rieures à quelques \%. Le mauvais usage des rodenticides en est la cause principale. Les experts s'accordent cependant sur le fait que quelle que soit leur nature - les produits de protection exercent une influence négative importante sur cette faune. II ne s'agit pas d'effets toxiques mais d'effets indirects : simplification du milieu (herbicides), effets privatifs de nourriture (insecticides)... II est possible de contrer de tels effets indirects en s'attachant à diversifier le paysage agricole (maintien des éléments fixes du paysage, des bordures, assolement...) et à éviter la dispersion des substances actives en dehors du champ où leur action est recherchée.

Un deuxième exemple peut être trouvé avec les arthropodes auxiliaires des cultures. Sur les plantes pérennes, un certain nombre d'insecticides anciens (ex : organophosphorés) ont été accusés à juste titre d'entraîner des proliférations de psylles ou d'acariens. L'innovation en matière d'insecticides et d'acaricides, jointe au progrès des techniques de lutte, a complètement transformé la donne au cours des dernières années. Ainsi en viticulture, l'emploi préférentiel d'insecticides sélectifs des typhlodromes du groupe des $\mathrm{RCl}^{6}$ et la pratique de la confusion sexuelle ont fait considérablement régresser l'emploi des acaricides spécifiques. Plus de 500000 ha du vignoble français recevaient un traitement acaricide en 1985. Cette intervention n'est plus aujourd'hui nécessaire que sur moins de 50000 ha, soit une régression de plus de $90 \%$ ! Sur le poirier, la pratique d'un traitement hivernal basé sur l'avertissement et les mesures destinées à favoriser les anthocoridés à partir des haies avoisinantes ont permis de faire chuter dans des proportions voisines le nombre des applications contre le psylle.

La durabilité de l'emploi des produits chimiques renvoie ainsi assez régulièrement vers l'importance qu'il y aurait à gérer le paysage agricole pour préserver les espèces non-cibles, tirer un bénéfice de leur activité et minimiser I'incidence possible des traitements sur la faune sauvage.

\section{Maintien de la fonctionnalité des sols}

L'étude de la relation entre vie des sols et produits chimiques est un thème ordinaire pour la prédiction des risques de contamination de l'eau et la constitution des dossiers d'AMM. Pour des substances anciennes susceptibles de conserver dans le sol une activité biologique, un critère tel que la durée de demivie est largement questionné. Ce fut le cas avec les anciens organochlorés aujourd'hui retirés. C'est toujours la situation des fongicides cupri-

\footnotetext{
${ }^{6} \mathrm{RCl}=$ Régulateurs de Croissance d'Insectes ; exemples : flufénoxuron, fénoxycarbe, lufénuron...
}

Tableau 3. Quelques valeurs guides relatives à la qualité des eaux de boisson.

\begin{tabular}{|llc|}
\hline \multicolumn{1}{|c|}{ Substances considérées } \\
\hline Norme EU & Toute molécule individualisée & $0,1 \mu \mathrm{g} / \mathrm{L}$ \\
& Ensemble des molécules et des métabolites & $0.5 \mu \mathrm{g} / \mathrm{L}$ \\
Valeurs OMS & Aldrine, dieldrine & $0,3 \mu \mathrm{g} / \mathrm{L}$ \\
& Atrazine, simazine, lindane & $2 \mu \mathrm{g} / \mathrm{L}$ \\
& Terbuthylazine, carbofuran & $7 \mu \mathrm{g} / \mathrm{L}$ \\
& Isoproturon & $9 \mu \mathrm{g} / \mathrm{L}$ \\
& Glyphosate & $900 \mu \mathrm{g} / \mathrm{L}$ \\
& AMPA & $900 \mu \mathrm{g} / \mathrm{L}$ \\
\hline
\end{tabular}

ques largement utilisés par la viticulture. Le cuivre est reconnu comme pouvant exercer une activité dépressive sur la vie du sol où il s'accumule au point d'occasionner des phytotoxicités en sol acide [19]. En 2003, la quantité utilisable par ha et par an a été limitée à $8 \mathrm{~kg} / \mathrm{ha}$ par la Commission européenne, puis réduite à $6 \mathrm{~kg} / \mathrm{ha} / \mathrm{an}$ au $1 \mathrm{er} \mathrm{janvier} 2006$.

Après la mise en application de la directive 91/414 européenne, on constate que la plupart des substances actives de synthèse aujourd'hui utilisées par nos agriculteurs sont à la fois fortement adsorbées et rapidement métabolisées (ex : folpel, pyréthrinoïdes). In fine, l'orientation actuelle de la pharmacopée chimique montre que les nouveautés présentent des risques pour la vie des sols généralement plus faibles et plus fugaces que les anciennes références.

Cela étant, la plupart des initiatives développées de par le monde pour garantir la conservation des sols à long terme reposent sur le travail du sol simplifié et le semis direct. Ces méthodes de culture en pleine expansion dépendent toujours de la possibilité d'utiliser avant semis des herbicides à spectre large peu persistants dont l'emploi avant semis vise à éliminer la flore présente, action qui, dans les systèmes de culture traditionnels, est procurée par un labour. Or, c'est ce même labour dont on cherche à réduire la fréquence pour sauvegarder la matière organique des horizons superficiels afin de favoriser la vie des sols et de conserver une structure qui limite l'érosion. En près de soixante ans de recherche, l'industrie n'a pu mener jusqu'à l'AMM que 4 substances actives capables de convenir à cet usage : amitrole, paraquat, glyphosate et glufosinate. Alors que l'une de ces substances vient d'être retirée et que les trois autres sont peu ou prou menacées de restrictions, on constate qu'il n'existe pas encore sous nos climats d'alternative à ces herbicides à spectre large, sans action sur la germination ultérieure des semences. Le maintien de la fonctionnalité des sols voudrait que l'on conserve le plus grand nombre de ces molécules rares afin de permettre la gestion à long terme du support des cultures.

\section{Protection de la qualité de l'eau}

La protection de l'eau est un sujet dont la prise en compte réelle ne débute qu'il y a une vingtaine d'années. En 1980, le Rapport Hénin avait provoqué une prise de conscience, mais il mettait d'abord l'accent sur les nitrates et non pas sur les produits de protection des plantes. À cela, deux raisons au moins: les méthodes $d^{\prime}$ analyse ne permettaient guère alors de descendre en dessous du $10^{\mathrm{e}}$ de ppm et la norme actuelle de qualité pour l'eau de boisson n'existait pas. Depuis lors, la capacité de détection des analyses s'est fantastiquement accrue et la norme de qualité des eaux de boisson fixée à $0,1 \mu \mathrm{g} / \mathrm{L}$ a lancé un débat qui n'est pas prêt de s'éteindre. Rappelons au passage que cette norme européenne est particulièrement exigeante en ce qui concerne les produits de protection des plantes et fixe un standard de qualité élevé. En regard, les valeurs OMS (VG ou Health Based Value), appréhendées molécule par molécule, donnent une image bien différente, ce qui explique en partie que le débat public, très vif dans I'Union européenne, soit souvent plus atténué dans d'autres grands pays agricoles (tableau 3 ).

Cela étant, la collecte des informations analytiques a été étendue à partir du début des années 90 et synthétisée grâce aux rapports IFEN. En 2002, cette compilation faisait état de 419664 analyses d'eaux souterraines sur 3873 stations de prélèvement et de 1148727 analyses d'eaux de surface sur 1948 stations de prélèvement. Malheureusement, ce rassemblement de données se borne à recenser des constats ponctuels et $n^{\prime}$ est pas encore à même d'autoriser des suivis dans le temps qui permettraient de pointer des évolutions positives ou négatives. Tout au plus peut-on constater que les détections de substances contaminantes comme les triazines tendent à s'affaisser depuis leur interdiction. En revanche, d'autres contaminants comme l'AMPA apparaissent plus fréquemment en raison du progrès analytique.

Au niveau de l'eau distribuée, I'AFSSA précisait récemment que « parmi les 752000 mesures de pesticides réalisées sur les eaux distribuées entre 
2001 et 2003, 7350 sont supérieures à la limite de qualité de $0,1 \mu \mathrm{g} / \mathrm{L} »^{7}$.

Différents mécanismes expliquent l'évasion d'une fraction des substances appliquées vers le milieu aquatique. On pense que les entraînements par ruissellement sont généralement dominants, devant les phénomènes de dérive et la percolation. II est clair aussi que les pollutions ponctuelles ont un impact prépondérant sur l'importance des contaminations. Des données communiquées en 2006 [20] par le Professeur H-G. Frede de I'Université de Giessen (Allemagne) montraient que dans 5 bassins versants de Hesse, les détections liées aux pollutions ponctuelles représentaient entre 65 et $95 \%$ du total observé. Après une formation des agriculteurs et l'adoption du rinçage des appareils au champ, une amélioration de 61 à $82 \%$ a été constatée !

En tout état de cause, il existe un consensus sur I'importance et la nécessité de réduire au maximum la dissémination des substances actives dans le milieu et sur le fait que la lutte contre les pollutions ponctuelles devient prioritaire. La durabilité des produits chimiques devrait à I'avenir être mieux garantie grâce à un faisceau d'actions convergentes dont la plupart sont déjà entamées :

- retrait ou encadrement plus strict des substances les plus problématiques, ce qui est le cas des principaux contaminants (triazines, urées substituées, lindane, carbofuran...) ;

- lutte résolue contre les pollutions ponctuelles par l'équipement des fermes en locaux de stockage au sol étanche, aires de remplissage, I'obligation faite de gérer les eaux souillées ;

- protection des aires de captage ${ }^{8}$ et mise à niveau des stations de traitement ;

- aménagements paysagers: des mesures comme les bandes enherbées, aujourd'hui pivot de la conditionnalité, ou les zones non traitées sont fondamentales pour capter les ruissellements et les dérives ;

- amélioration à venir du matériel d'application: équipements en buses à limitation de dérive, contrôle des appareils et rénovation du parc de pulvérisateurs...

Les mesures récentes vont toutes dans le bon sens mais les réglementateurs auront-ils la patience d'attendre le constat des résultats positifs qu'elles ne manqueront pas de produire sitôt leur adoption par une majorité d'agriculteurs?

\footnotetext{
${ }^{7}$ Avis de l'AFSSA du 8 juin 2007

${ }^{8}$ D'après le MEDAD, $37 \%$ seulement des ressources en eau potable disposent aujourd'hui de périmètres de protection.
}

\section{Attentes sociétales, protection chimique} et durabilité

Les réflexes qui sous-tendent les attentes sociétales vis-à-vis de la chimie en protection des cultures semblent rejoindre d'autres secteurs où science et progrès s'efforcent d'aller de pair : génétique, microtechnologies, nucléaire civil... Dans notre domaine, les éléments de rejet relèvent en général de la crainte ordinaire de l'inconnu entretenue par une méconnaissance profonde de la chimie, une suspicion sur la qualité de la nourriture et une ignorance des techniques agricoles et des raisons d'être de la protection des cultures.

Parmi les éléments factuels qui génèrent ces appréhensions et encouragent la pression réglementaire, nous retiendrons trois aspects : la sécurité des personnes, les résidus dans l'alimentation, et une vision fragmentaire et passéiste de ce que sont les produits phytopharmaceutiques.

\section{Sécurité des personnes}

Les questions autour de la sécurité pour I'homme ne sont pas nouvelles. Dès le début de l'emploi des produits chimiques pour la protection des plantes, certains se sont effrayés des conséquences pour le manipulateur des décoctions de tabac ou du sulfate de cuivre en trempage des semences [21]. Il en fut de même lors de la mise au point de la bouillie bordelaise qui faisait craindre l'empoisonnement des amateurs de vin. À cette époque les travaux analytiques d'Ulysse Gayon à Bordeaux contribuèrent à tranquilliser le public. Puis le débat a été relancé avec l'arrivée du doryphore et les insecticides à base d'arsenic.

Dans ce domaine, la demande constante des utilisateurs et des autorités pour la mise au point de produits moins irritants et moins toxiques a été suivi de résultats très concrets mais hélas peu connus. Dans un domaine aussi spécialisé, il est certain que les critères qui permettent de classifier une substance sont peu compréhensibles pour le non-expert. Un critère simple, voire simpliste, comme la DL 50 orale sur rat mâle, même s'il est très insuffisant pour mesurer les risques que peut représenter une spécialité pour l'utilisateur, est cependant facilement accessible pour les substances actives et peut aider à retracer le sens des évolutions au sein de la pharmacopée.

L'accroissement régulier au fil du temps de la moyenne des valeurs de DL 50 des substances actives qui composent la pharmacopée chimique reflète un axe constant de la recherche. La réduction du danger potentiel - et des risques associés - constitue en effet l'une des priorités des laboratoires. Cette tendance est bien illustrée au sein du groupe des insecticidesacaricides qui rassemble les substances réputées les plus nocives. Le tableau 4 montre une évolution considérable vers des agents actifs dont les spécialités dérivées auront moins de chance d'être classées (figure 4).

Cette approche très fragmentaire demanderait bien sûr à être largement complétée, en particulier sur des critères issus de l'expérience comme la DJA. II en est de même pour tout ce qui concerne la gestion des risques au niveau de l'utilisateur. Un effort nouveau pour la formation a été entrepris ces dernières années mais ce secteur connaît encore un certain retard par rapport à nos voisins les plus avancés.

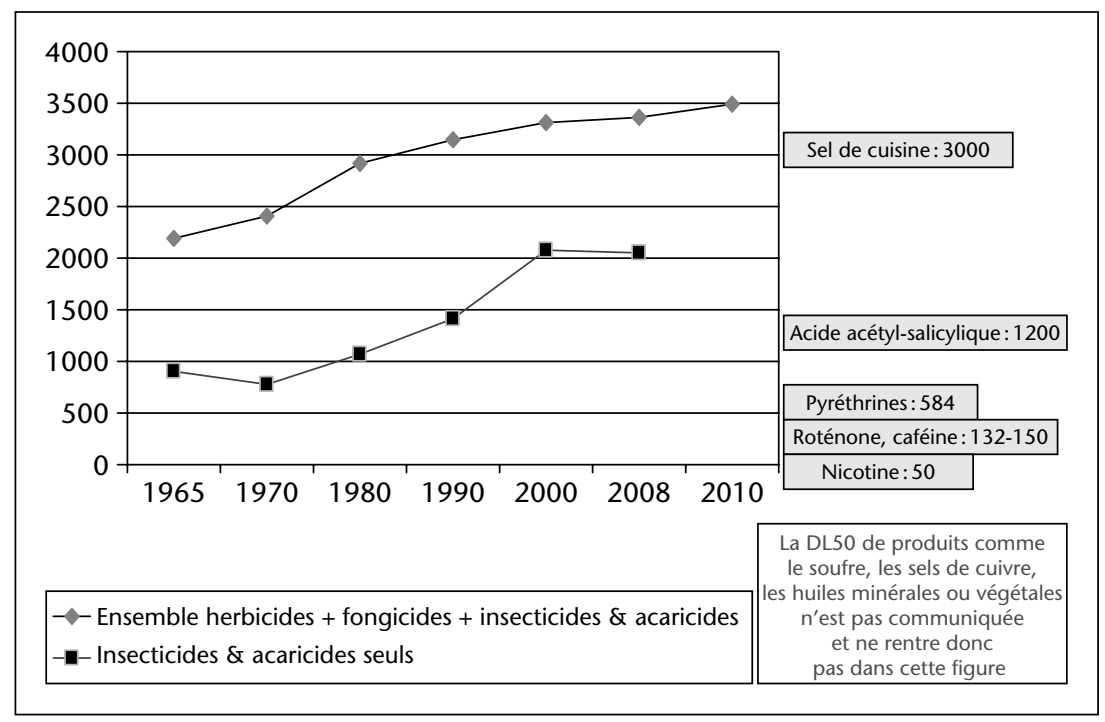

Figure 4. Evolution 1965-2008 de la DL 50 moyenne par ingestion des substances actives chimiques autorisées. 
Tableau 4. Nombre de substances actives insecticides et/ou acaricides autorisées à la vente par classe de DL50 orale (rat mâle) pour 3 années repères.

\begin{tabular}{|c|c|c|c|c|c|c|}
\hline & \multirow[b]{2}{*}{ Nb de substances actives } & \multicolumn{5}{|c|}{ Classes de DL 50 rat $\delta \hat{~}$} \\
\hline & & $1-50$ & $51-100$ & $101-500$ & $501-2000$ & $>2000$ \\
\hline 1965 & 68 & 27 & 6 & 17 & 11 & 7 \\
\hline 1990 & 109 & 33 & 17 & 27 & 12 & 20 \\
\hline 2008 & 72 & 8 & 11 & 22 & 8 & 22 \\
\hline
\end{tabular}

\section{Résidus}

Dans les médias occidentaux, les reproches faisant état d'une alimentation «bourrée de résidus » ne sont pas rares. Rien ne semble plus faux.

Comme l'eau, notre alimentation fait l'objet d'une surveillance régulière et bénéficie du progrès constant des méthodes d'analyse. Avec le temps, plus de substances actives sont recherchées et les niveaux détectables sont de plus en plus ténus. Bien que l'orientation des contrôles varie sensiblement d'un pays à l'autre, ciblant avec plus ou moins de constance les denrées importées qui sont régulièrement sujettes à plus de cas de dépassement de la LMR (limite maximale de résidus pour la denrée considérée) que les denrées produites sur le sol national. Les résultats regroupés sur 8 années par la Commission européenne montrent de solides constantes (figure 5):

- plus de $59 \%$ des produits frais, bien que traités, ne contiennent aucun résidu décelable ;

- $36 \%$ environ permettent de retrouver des traces en dessous des limites autorisées ;

- 4 à $5 \%$ excèdent la LMR.

Ces deux derniers groupes focalisent régulièrement l'ire des opposants de la chimie...
Pour une immense majorité de la communauté scientifique au fait du sujet, une polémique sur la santé du consommateur n'a guère lieu d'être en raison du faible pourcentage des dépassements et des énormes coefficients de sécurité qui sont pris pour fixer une LMR. Rappelons qu'à partir de batteries de tests in vivo, on détermine pour chaque substance active une dose sans effet (DSE) établie à partir de la dose maximale pour laquelle on $n^{\prime}$ observe à court et long terme aucun effet décelable chez l'animal le plus sensible. Cette donnée affectée d'un coefficient de sécurité de 100 au minimum conduit à la notion de dose journalière admissible (DJA) : elle correspond à la quantité maximale de substance active pouvant être ingérée quotidiennement par un individu durant toute sa vie, sans conséquence pour sa santé. Les LMR existent pour l'ensemble des usages $d^{\prime}$ 'une substance active et leur addition ne doit jamais dépasser la DJA. La procédure d'établissement de ces normes est largement internationalisée et leurs niveaux, qui tiennent compte des habitudes alimentaires des différents pays, tendent heureusement à s'uniformiser.

Pour l'avenir et dans l'intérêt du consommateur inquiet, il serait important de bien expliciter les enquêtes périodiques qui, dès leur paru-

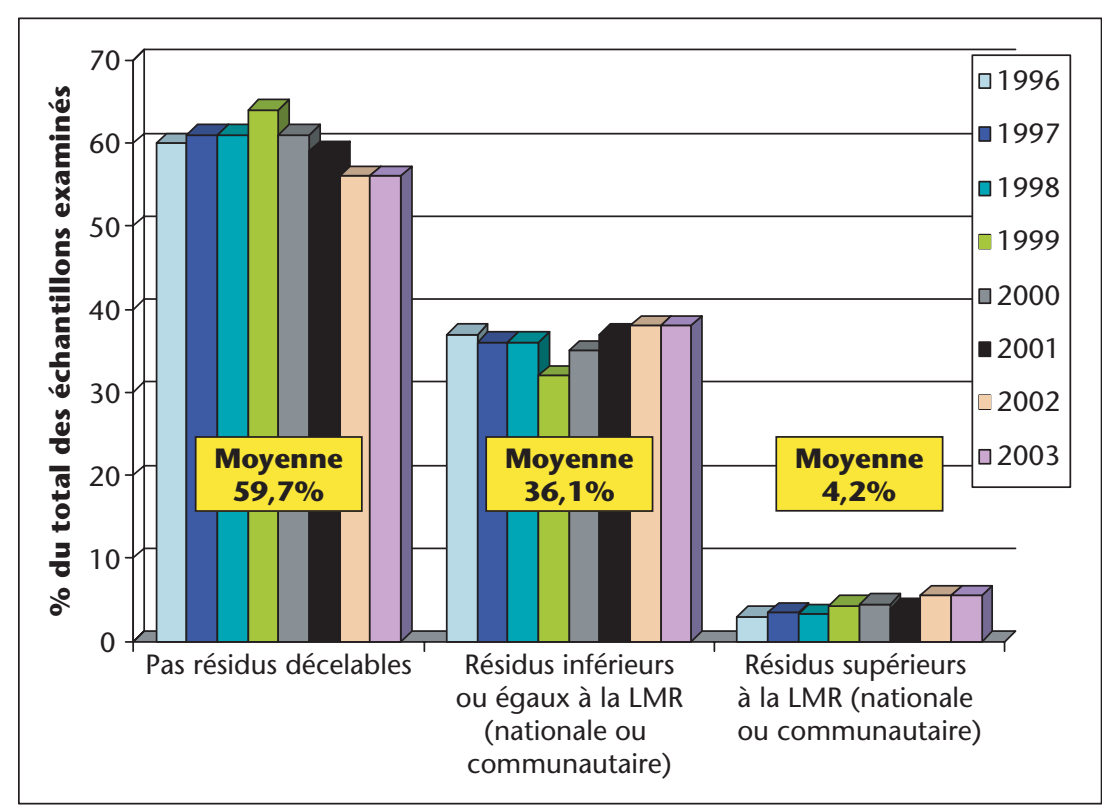

Figure 5. Résultat de 8 années de contrôle en Europe sur les niveaux de résidus dans les fruits et legumes. Source: Commission européenne. tion, sont soumises en France à des attaques médiatiques qui font plus de place à l'activisme qu'à la science. Pour cela, il serait judicieux de $s^{\prime}$ inspirer de la manière dont les experts américains de la Food \& Drug Administration (FDA) émettent périodiquement leurs données. Dès leur sortie, des présentations très complètes, facilement accessible sur Internet ${ }^{9}$, s' $^{\prime}$ efforcent en particulier de clarifier la raison des dépassements. On constate que :

- soit le produit n'est pas autorisé sur la culture mais possède une autorisation de vente sur d'autres cultures : c'est ce que l'on appelle la déviation d'usage, attribuée à une négligence, voire à un manque de connaissances professionnelles;

- soit le produit est autorisé mais dépasse la LMR nationale : il s'agit en général d'un dernier traitement trop tardif, d'un appareillage mal réglé, de laxisme ;

- soit le produit n'est pas autorisé dans le pays importateur mais son niveau de détection est conforme à la LMR du pays d'origine des denrées: traduction $d^{\prime} u n e$ mauvaise traçabilité, d'une absence de cahier des charges ;

- soit le produit n'a aucune AMM dans le pays d'origine voire n'est pas un produit de protection des cultures répertorié : il s'agit alors souvent d'une fraude.

Pour assurer la durabilité des solutions chimiques, il est important d'informer complètement le consommateur dans le domaine des résidus. Cette nécessaire pédagogie doit s'accompagner d'un véritable souci de transparence car, à notre connaissance, ces données ne sont pas publiées pour l'ensemble des filières de production.

\section{Méconnaissance des caractéristiques de la pharmacopée}

Ce point est en partie corrélé au précédent mais nous souhaitons attirer fortement l'attention sur les préjugés qui naissent par suite d'une méconnaissance ordinaire de la pharmacopée chimique. Elle est fréquente chez beaucoup d'agronomes de formation non spécialisés dans cette branche mais confine à l'ignorance la plus totale au niveau de bon nombre de

\footnotetext{
${ }^{9}$ Voir par exemple: www.cfsan.fda.gov/ dms/ pes03rep.html
} 
Tableau 5. Segmentation chimique des différentes solutions phytosanitaires destinées à des usages agricoles (source : E. Barrié).

\begin{tabular}{|c|c|c|c|c|c|c|c|c|c|}
\hline & & \multirow{3}{*}{$\begin{array}{l}\text { Produits } \\
\text { minéraux }\end{array}$} & \multirow{3}{*}{$\begin{array}{c}\text { Produits } \\
\text { organo- } \\
\text { métalliques }\end{array}$} & \multicolumn{5}{|c|}{ Produits organiques } & \multirow{3}{*}{$\begin{array}{l}\text { Organismes } \\
\text { vivants } \\
\text { Organismes } \\
\text { vivants }\end{array}$} \\
\hline & \multirow[b]{2}{*}{$\begin{array}{c}\text { Nb de } \\
\text { substances } \\
\text { examinées }\end{array}$} & & & \multirow[t]{2}{*}{$\begin{array}{l}\text { Huiles fossiles } \\
\text { et végétales }\end{array}$} & \multirow[t]{2}{*}{$\begin{array}{l}\text { Extraits } \\
\text { naturels }\end{array}$} & \multicolumn{2}{|c|}{$\begin{array}{c}\text { Molécules produites } \\
\text { par synthèse }\end{array}$} & \multirow[t]{2}{*}{$\begin{array}{l}\text { Produits de } \\
\text { fermentation }\end{array}$} & \\
\hline & & & & & & $\begin{array}{c}\text { Mimétiques } \\
\text { de produits } \\
\text { naturels }\end{array}$ & $\begin{array}{c}\text { Issus } \\
\text { de criblage } \\
\text { systématique }\end{array}$ & & \\
\hline 1970 & 269 & 11 & 15 & 4 & 4 & 4 & 231 & 0 & 0 \\
\hline 1975 & 317 & 9 & 15 & 5 & 4 & 10 & 273 & 0 & 1 \\
\hline 1980 & 334 & 8 & 9 & 5 & 4 & 10 & 297 & 0 & 1 \\
\hline 1985 & 369 & 8 & 12 & 6 & 5 & 14 & 315 & 3 & 6 \\
\hline 1990 & 416 & 8 & 10 & 5 & 8 & 26 & 351 & 4 & 4 \\
\hline 1995 & 462 & 7 & 8 & 6 & 9 & 33 & 370 & 6 & 23 \\
\hline 2000 & 533 & 8 & 9 & 9 & 10 & 46 & 396 & 8 & 47 \\
\hline 2005 & 438 & 7 & 5 & 7 & 11 & 41 & 315 & 8 & 44 \\
\hline
\end{tabular}

décideurs. Sans évoquer plus longuement les journalistes et le grand public.

Un mot très bref sur les aspects quantitatifs qui ont fait et font débat. La consommation des produits chimiques a pris son envol vers 1855 . Entre 2000 et 2006, leur utilisation annuelle a porté sur 99000 à 71000 t de substances actives. De brèves recherches montrent que l'agriculture française en demandait plus de 250000 t sur la période 1910-1913 (acide sulfurique compris). Durant la période des pénuries de la Grande Guerre, leur emploi a chuté à moins de $100000 \mathrm{t} / \mathrm{an}$ avant de remonter à plus de $250000 \mathrm{t} /$ an entre 1920 et 1923 . Plus près de nous, les données CSP rapportées en 1952 par le ministère de l'Agriculture ${ }^{10}$ suggèrent qu'elles n'étaient pas inférieures à 160000 t sur la campagne céréalière 1951 . 1952, à une époque où tout le monde déplorait une relative pénurie en produits de lutte.

Depuis Millardet, la nature de ces produits chimiques a fortement évolué, ainsi que leurs caractéristiques et les risques associés. Dans une synthèse [15] dressée en 2005, nous pouvons constater :

- que les produits minéraux et organométalliques hérités des origines de la pharmacopée moderne sont numériquement en régression et rien ne permet de prévoir un renouveau dans ce domaine. Les principaux restent le soufre et les différents sels de cuivre, essentiellement confinés aux cultures pérennes ou à des usages ponctuels très particuliers (tableau 5);

- que les extraits naturels progressent; certains sont en voie de disparition comme la roténone, d'autres apparaissent comme la laminarine ; mais leur emploi reste marginal en raison d'une

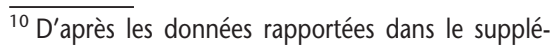
ment au n ${ }^{\circ} 77$ de la Revue du ministère de l'Agriculture de 1952.
}

efficacité jugée souvent trop faible ou irrégulière ;

- que les molécules de synthèse ont une évolution contrastée: des retraits consécutifs à la mise en application de la directive 91/414 CE pour diverses molécules issues de la synthèse classique et un nombre croissant de substances crées à partir de la structure de molécules naturelles actives (entrent dans ce groupe les pyréthrinoïdes, les $\mathrm{RCl}$, les herbicides de type callistémone, tricétone...) ;

- l'apparition des organismes vivants concerne Bt, Bacillus subtilis... mais surtout de nombreux arthropodes auxiliaires aujourd'hui couverts par la procédure d'AMM.

Dans le secteur de la lutte contre les ravageurs, cette évolution apparaît clairement (figure 6). Mais cette apparente diversification, si elle rend $d^{\prime}$ immenses services en cultures sous abris avec la mise en œuvre coordonnée de moyens chi- miques et d'arthropodes auxiliaires, est peu opérante dans le secteur des cultures pérennes et surtout des grandes cultures. Les insecticides chimiques y restent encore incontournables en cas de besoin mais leur variété diminuant rapidement, les agriculteurs pourraient se trouver confrontés à des phénomènes de résistance difficiles à contourner. C'est déjà le cas pour les méligèthes du colza.

De même, le désherbage chimique des céréales au moyen d'herbicides sélectifs qui reste - faute de mieux - la norme dans tous les pays développés connaît des difficultés croissantes. Dans certains pays du nord de l'Europe, l'élimination prématurée de certains herbicides pondéreux a conduit à un usage massif des sulfonylurées à faible grammage et à une flambée de phénomènes de résistance chez des dicotylédones banales. En France, des inquiétudes se font jour avec le choix des graminicides qui se restreint

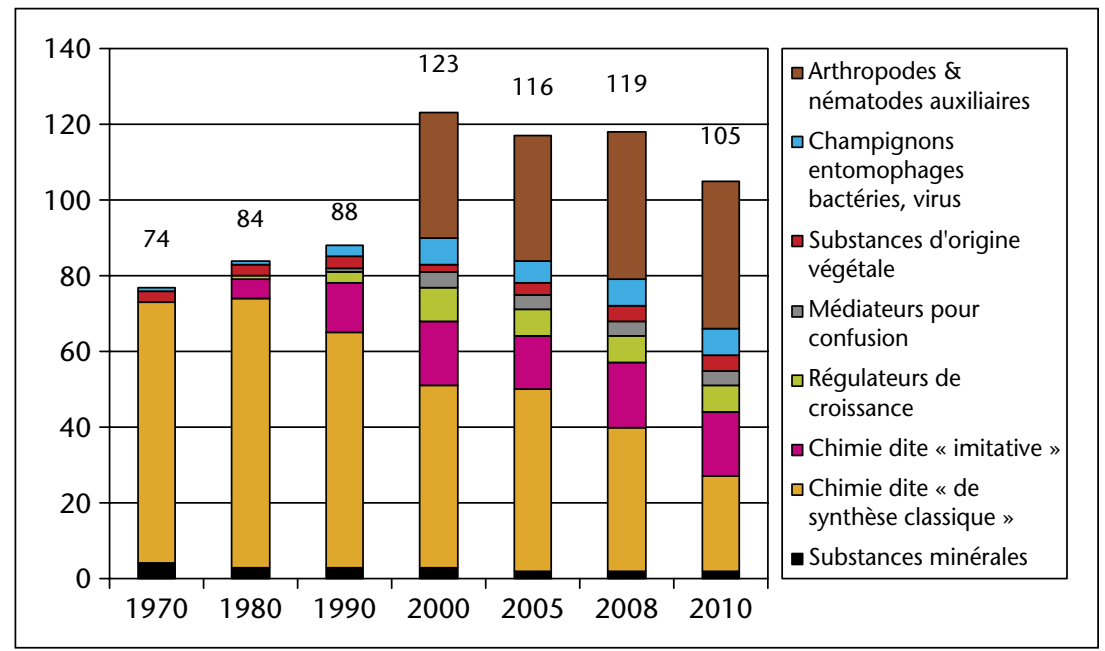

Figure 6. Nombre de solutions autorisées en France pour la protection des cultures de plein air contre les ravageurs (insectes et acariens).

Source : information compilée à partir des données de l'index phytosanitaire ACTA. 
et peut rendre délicat à terme le désherbage sélectif contre le ray-grass, le vulpin ou la folleavoine dans un contexte de résistances déjà établies.

\section{Conclusion}

Dans le cadre de notre communication, s'interroger sur la manière dont la chimie peut favoriser une protection durable des cultures équivaut d'abord à poser quelques principes avant d'esquisser des pistes de progrès.

À nos yeux, il est certain tout d'abord que la protection des cultures n'est pas un luxe de pays riche mais un exercice obligatoire si l'on veut assurer la sécurité des approvisionnements. Elle ne peut et ne doit en aucun cas viser à l'éradication du parasitisme. En revanche, son objectif est de limiter de façon régulièrement satisfaisante les dégâts quantitatifs et qualitatifs qu'il engendre pour les maintenir en dessous du niveau où la durabilité économique des exploitations serait compromise.

Pour cela, la protection des plantes cultivées doit faire appel à toute la palette des moyens existants, y compris les mesures indirectes de protection. Ces mesures, parfois considérées comme passéistes, ont généralement montré leurs limites dans les siècles écoulés. La mise en œuvre de certaines d'entre elles demeure cependant incontournable si l'on veut éviter de faire reposer tout le poids de la protection des cultures sur les moyens directs d'intervention dont dispose l'agriculteur. Négliger ces mesures indirectes tend à intensifier l'emploi de moyens directs contre une pression accrue des bioagresseurs, avec une augmentation des effets indésirables.

Nous rappellerons encore que la chimie n'est pas la protection des cultures mais à notre avis, une protection économique des productions végétales ne peut guère s'en passer. Pour que les produits phytopharmaceutiques puissent jouer un rôle effectif et durable dans le dispositif, il convient de préserver l'existence d'une pharmacopée large et diversifiée. Même en ajustant au mieux le nombre de traitements chimiques ou biologiques, en calibrant avec précision les méthodes de contrôle physiques (ou mécaniques), le recours répétitif aux mêmes solutions provoque des dérives dans les populations de bioagresseurs qui transforment avec le temps des aléas passagers en problèmes récurrents difficiles à résoudre (effets favorisant sur des ravageurs mineurs, inversion de flore, résistances...).

Nous devons, en outre, être persuadés que dans ce domaine, aucune intervention humaine n'est dénuée d'effet environnemental. Remplacer par principe un herbicide non sélectif utilisé en présemis par un labour génère sur les populations de lombriciens ou d'arach- nides des effets négatifs qui auraient été perçus comme intolérables venant d'un produit chimique. De même lorsqu'on s'interroge sur l'impact d'un défanant chimique des pommes de terre sur les insectes présents dans le couvert, on oublie généralement de se poser la même question lorsque le défanage thermique est présenté comme alternative écologique... II est très important pour l'avenir de sortir de cette forme d'hémiplégie. Une attitude plus adulte et conséquente consisterait à privilégier des approches n'exerçant que des effets limités et transitoires sur la diversité du vivant inféodé à l'écosystème agricole préexistant, sans I'hypothéquer à moyen et long terme.

Parmi les pistes de progrès nous souhaitons souligner trois aspects.

Tout d'abord l'importance de la prise en compte du paysage agricole. Les bandes enherbées, les haies, les talus, les arbres isolés... ont des rôles multiples. Parties intégrantes de l'écosystème agricole, ils interviennent dans le cycle de l'eau, la vie de nombreuses espèces et sont à la fois des éléments positifs pour la qualité de l'eau, la conservation des sols... et la mise en pratique d'un système de production intégrée. Leur existence et leur saine gestion contribuent à rationaliser les interventions, à donner de la durabilité aux moyens chimiques de protection et à l'ensemble du système productif.

Un autre aspect est la formation des hommes. Avec la prise de conscience des contraintes et des limites des outils chimiques, la protection des cultures est sortie des approches simplistes qui avaient encore cours dans un passé récent. Positionner systématiquement un produit phytopharmaceutique comme première réponse à un problème donné ne paraît plus être la démarche souhaitable. Mais le simple fait de devoir embrasser plus largement le champ des connaissances pour proposer des solutions durables représente un exercice nouveau et nécessite des efforts certains. Y compris pour le conseiller ou l'enseignant qui doivent faire œuvre de pédagogie. Ce renouveau de la formation, déjà perceptible dans les démarches nouvelles, est absolument impératif pour hâter l'adoption des nouveaux concepts.

Un dernier aspect à multiples facettes est la communication. Elle concerne beaucoup de monde autour de notre sujet, mais au premier chef sans doute, les scientifiques. Sur bien des aspects, on constate que I'opinion publique tire son information de lanceurs d'alerte quasi professionnels sans que la communauté des experts scientifiques soit audible. II est sans doute du rôle de ces derniers de se mobiliser pour donner plus d'équilibre à l'information publique, sans que cela éteigne l'indispensable débat entre experts.
Parmi les points cruciaux de l'exercice, je voudrais en proposer deux à votre réflexion.

Nous savons tous que les laboratoires publics et privés investissent lourdement pour mettre au point des méthodes d'analyse de plus en plus sensibles, capables de repérer des traces infinitésimales de substances chimiques à des niveaux ou un quelconque effet biologique paraît inimaginable. Or, de telles détections sont presque systématiquement présentées comme porteuses de risques évidents pour la population. La communication est donc pervertie parce que la détection d'un epsilon de quelque chose que l'on recherche précisément est assimilée avec un risque objectif. D'où une fuite en avant parfois traduite par la boutade : « avec le temps, le zéro devient de plus en plus petit ». Et notre débat du jour ne concerne que les «pesticides». Que sera demain I'opinion publique après la mise en place des procédures REACH ${ }^{11}$ ?

Enfin, j'ai pu souvent vérifier que l'utilisation de moyens chimiques pour la protection des cultures avait une acceptation sociétale d'autant plus réduite que les idées reçues lui opposent comme alternative une agriculture biologique bénéficiant d'un présupposé sans traitements. Ce qui n'est évidemment pas la vérité.

Dans ces domaines de communication et dans bien d'autres, le scientifique devra se faire vulgarisateur pour calmer les peurs et clarifier les options forcément techniques de l'agriculture de demain. Au-delà de la protection des plantes, il en va de l'acceptation sociétale de l'agriculture en général.

\section{RÉFÉRENCES}

1. REDI F. Esperienze intorno alla generazione degli insetti. 1668.

2. LE BERRYAIS R. Le Traité des Jardins, ou le nouveau de La Quintinye, contenant la description et la culture. 1785.

3. BOULAINE J, LEGROS JP. D'Olivier de Serres à René Dumont, portraits d'agronomes. 1998.

4. TILLET M. Dissertation sur la cause qui corrompt et noircit les graines du bled dans les épis et sur les moyens de prévenir ces accidents. 1755.

\footnotetext{
${ }^{11}$ Le règlement européen REACH propose de combler le déficit de connaissances des risques environnementaux et sanitaires qui peuvent résulter de la production et de l'utilisation des 100000 substances chimiques utilisées en Europe. Dans les 10 années à venir, 30000 de ces substances seront soumises à un examen qui est déjà réalisé en profondeur depuis longtemps pour les substances phytopharmaceutiques.
} 
5. PREVOST B. Mémoire sur la cause immédiate de la carie ou charbon des blés et de plusieurs autres maladies des plantes et sur les préservatifs de la carie. 1807.

6. BRENT KJ. One hundred years of fungicide use. Fungicides for crop protection. BCPC monograph $1985 ; 31: 11$.

7. GEOFFRION R. Le soufre et l'arboriculture fruitière à pépins. In : CR du Symposium international du soufre élémentaire en agriculture. 1987 ; (1: 211).

8. LHOSTE J, LAMBERT J. In : Les fongicides. 1970 : 157-8.

9. HOWARD LO. CR des séances de l'Académie d'Agriculture de France. 1910 : $489 ;$ 569-572.

10. BERNARD JL. Le désherbage sélectif des cultures a 100 ans. Phytoma-LDV $1996 ; 486$.

11. RABATE E. La destruction des mauvaises herbes. 1927.
12. BERNARD JL. Le soufre et la protection des cultures. Hier, aujourd'hui, demain. CR séance de I'Académie d'Agriculture de France, 13 juin. 2007.

13. DEHERAIN PP. In : Les plantes de grande culture. $1898: 117$

14. BERNARD JL, BUGARET Y. La prophylaxie et les méthodes de lutte indirecte en protection des cultures. $2^{e}$ Conf. Inter. sur les moyens alternatifs de lutte contre les organismes nuisibles aux végétaux. Lille : AFPP, 2002 ; (4-7 mars).

15. BARRIE E. Evolution de la pharmacopée phytosanitaire française. Mémoire de stage de première année, Mastère de Biotechnologies, université de Paris-Sud. 2005.

16. BIBARD V, NICOLIER S, RENOUX JP. Les stratégies de désherbage du maïs. Phytoma-LDV $2007 ; 603$.
17. BLOGOWSKI A. Politique agricole commune et réduction des risques liés aux pesticides. Colloque AFPP-SWAP-CCP, Protection des eaux de surface contre les transferts diffus de produits phytosanitaires, Paris, 15-16 novembre 2007.

18. STREITO JC, MARTINEZ M. Nouveaux ravageurs. Phytoma-LDV $2005 ; 586$.

19. BRUN L. Etude de l'accumulation, de la biodisponibilité et de la phytotoxicité du cuivre dans les sols viticoles de l'Hérault. Thèse Ecole nationale supérieure agronomique de Montpellier. 1998.

20. FREDE HG. TOPPS Forum Germany. 2006; (Octobre).

21. FEBURIER. Rapport sur les moyens proposés jusqu'à ce jour pour préserver les blés de la carie. Extrait des mémoires publiés par la Société d'Agriculture et des Arts de Seine-etOise, depuis sa séance publique du 9 juillet 1820, jusqu'à celle du 15 juillet 1821. 